\title{
SEGMENTATION OF WATER BODY GIVEN PROBABILITY OF OCCURRENCE OF WIND DIRECTION BY CIRCULAR OR ELLIPTIC DISTRIBUTION
}

\author{
Masumi Serizawa' ${ }^{1}$ Takaaki $\mathrm{Uda}^{2}{ }^{2}$ and Shiho Miyahara ${ }^{2}$ \\ In a slender water body with a large aspect ratio, the angle of wind waves relative to the direction normal to the \\ shoreline may exceed $45^{\circ}$, resulting in the emergence of cuspate forelands and the segmentation of a lake, because the \\ fetch distance along the principal axis becomes large. The BG model was used to predict the segmentation of a \\ rectangular water body by wind waves when the probability of occurrence of wind direction is given by a circular or \\ elliptic distribution. The changes in wave field and sand transport flux over time were calculated to investigate the \\ wave-sheltering effect of the cuspate forelands. A rectangular lake segmented into circular or elliptic lake, when the \\ probability of occurrence of wind direction is given by a circular or elliptic distribution, respectively.
}

Keywords: cuspate foreland; water body; wind waves; segmentation; BG model; lakeshore changes

\section{INTRODUCTION}

In a narrow water body with a large aspect ratio, the angle of wind waves relative to the direction normal to the shoreline may exceed $45^{\circ}$, and the shoreline may become unstable because the fetch distance in the direction of the principal axis of the water body is sufficiently large for waves with significant energy to be generated (Ashton et al. 2001; Ashton and Murray 2006). Therefore, cuspate forelands that develop from both shores of a narrow water body connect with each other, resulting in the segmentation of the water body into smaller rounded lakes (Zenkovich 1967; Ashton et al. 2009). For example, Fig. 1 shows the segmentation of a lagoon facing the Chukchi Sea in Russia (Zenkovich 1967; Ashton et al. 2009). In this example, as a result of segmentation, five elliptic lakes can be observed, and their axes are parallel to each other. Figure 2 shows an enlarged satellite image of the rectangular area in Fig. 1, and in this image, lake segmentation can be seen, but it is a primitive stage with the alternate development of cuspate forelands. Regarding these phenomena, the division and reduction of fetch distance owing to the formation of a large shoreline protrusion associated with shoreline instability under high-wave-angle conditions and the resulting change in the wave field are key factors. Ashton et al. (2009) developed a model for predicting lakeshore changes on the basis of a longshore sand transport equation, and predicted that the forelands formed along the shoreline connect with each other, resulting in the segmentation of the water body into smaller rounded lakes. Uda et al. (2012) predicted the three-dimensional (3-D) segmentation of a shallow rectangular water body using the BG model (a 3-D model for predicting beach changes based on Bagnold's concept). Uda et al. (2013) studied the emergence and mergence of small lakes and their segmentation using the same model. They assumed that the wind blew from all directions between 0 and $360^{\circ}$ with the same probability of occurrence and intensity, that is, a circular distribution of the probability, and obtained circular segmented lakes. The segmentation into elliptic shapes, as shown in Fig. 1, was not carried out in their study. It may be accomplished under the condition that the probability of occurrence of wind direction is given by elliptic distribution, similarly to the case of oriented lakes (Uda et al. 2014). In addition, in previous studies (Uda et al. 2012; 2013), the change in wave field and sand transport flux associated with topographic changes were unclear. In this study, not only the segmentation of a rectangular lake but also the changes in wave field and sand transport flux were calculated, given a circular or elliptic distribution of the probability of occurrence of wind direction.

\section{CUSPATE FORELANDS FORMED IN LAKE KITAURA}

Lake Kitaura located in Ibaraki Prefecture is a shallow lake with an area of $35.2 \mathrm{~km}^{2}$ and $25 \mathrm{~km}$ length in the north-south direction, as shown in Fig. 3. This lake is located in the lowland surrounded by Kashima and Namegata tablelands with elevations of 40 and $30 \mathrm{~m}$ on the east and west sides, respectively. Thus, wind waves can be generated without a significant sheltering effect by hills or mountains. Figure 4 shows the wave rose obtained from meteorological observations between 1978 and 2004 at the center of Lake Kasumigaura, as shown in Fig. 3. Because the direction of the principal axis of Lake Kitaura is $\mathrm{N} 18^{\circ} \mathrm{W}$, the predominant wind of NNE blows at an angle of $40.5^{\circ}$ clockwise relative to the direction of the principal axis. Because of this oblique wind direction, wind waves are incident at a large incidence angle to the shoreline, resulting in the formation of the protruding shoreline on the west shore. In particular, an enlarged satellite image of two subareas, $\mathbf{a}$ and $\mathbf{b}$, in Fig. 3 is shown in Fig. 5. In subarea a, cuspate forelands and the ridges develop out of phase, and this condition is very similar

\footnotetext{
${ }^{1}$ Coastal Engineering Laboratory Co., Ltd., 1-22-301 Wakaba, Shinjuku, Tokyo 160-0011, Japan

${ }^{2}$ Head, Shore Protection Research, Public Works Research Center, 1-6-4 Taito, Taito, Tokyo 110-0016, Japan
} 
to that in the lagoon facing the Chukchi Sea, as shown in Fig. 2. Similarly, the cuspate forelands on both shores extend out of phase in subarea $\mathbf{b}$.
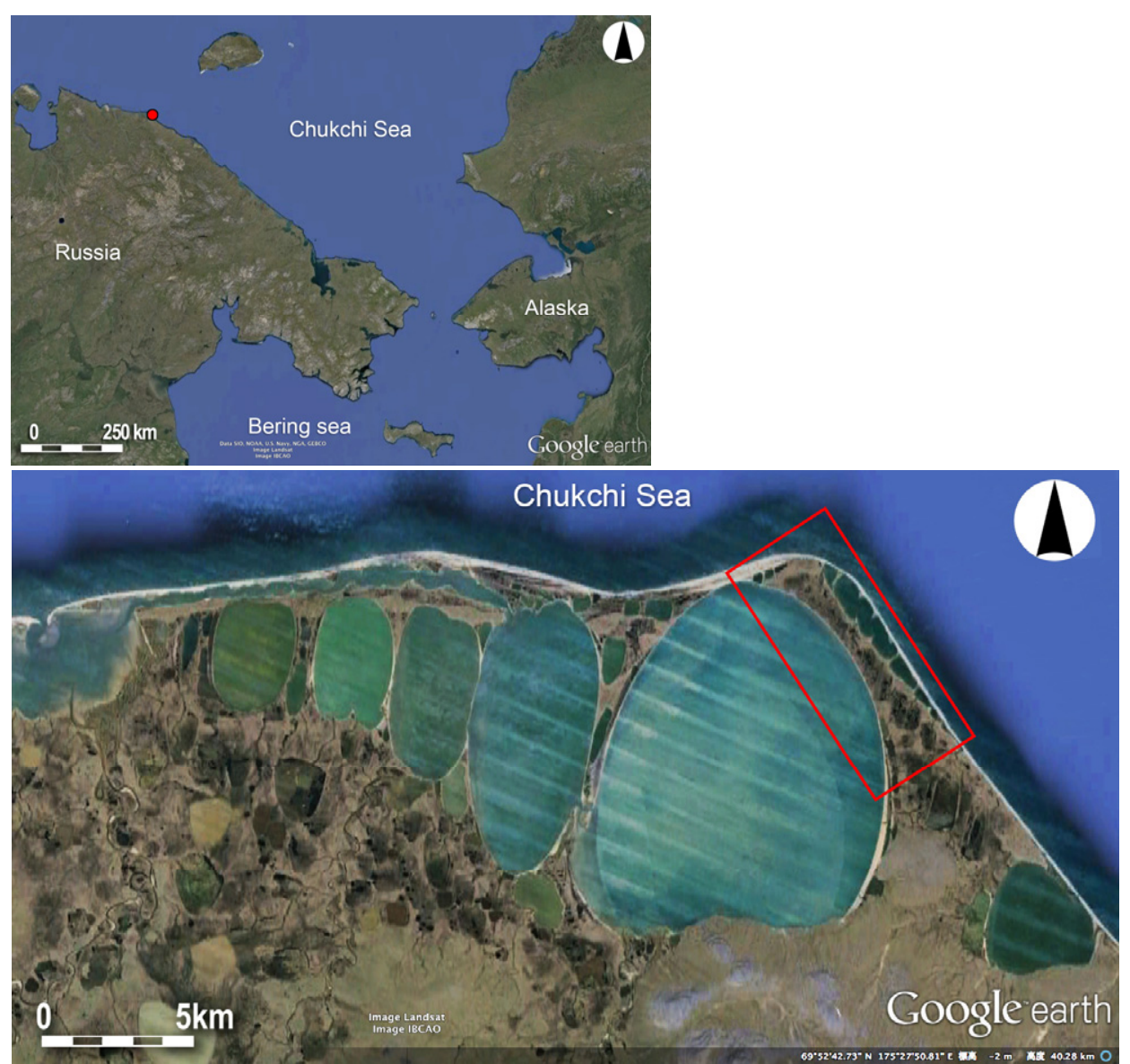

Figure 1. Example of segmentation of slender water body: lagoons facing Chukchi Sea (Zenkovich 1967; Ashton et al. 2009).

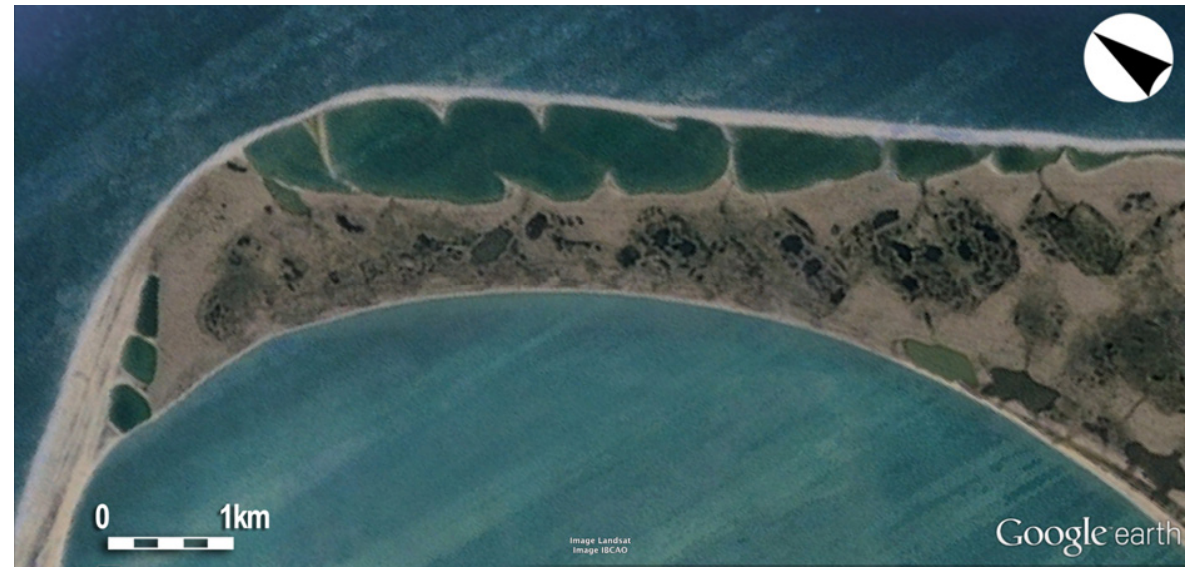

Figure 2. Enlarged satellite image of rectangular area in Fig. 1. 


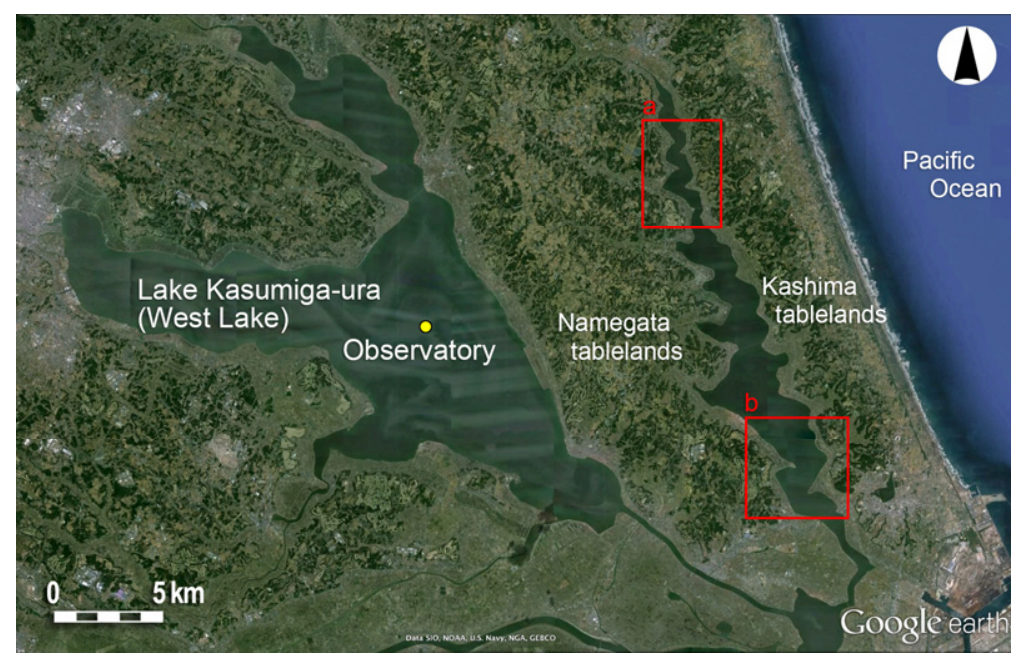

Figure 3. Cuspate forelands developed along lakeshore of Lake Kitaura in Ibaraki Prefecture, Japan.

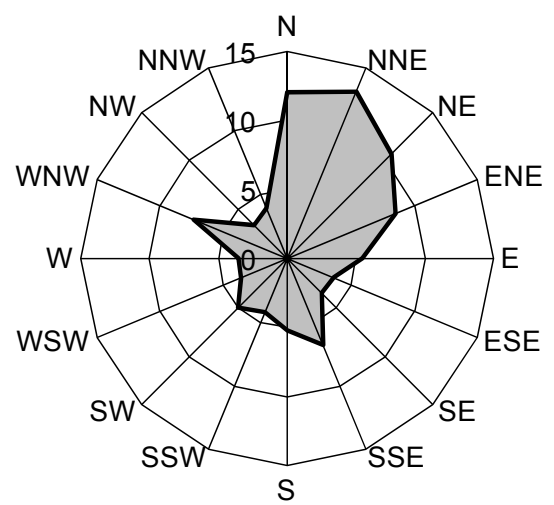

Probability of occurrence of daily maximum wind velocity measured between 1978 and 2004

Figure 4. Wind rose measured at observatory in center of Lake Kasumiga-ura, as shown in Fig. 3.
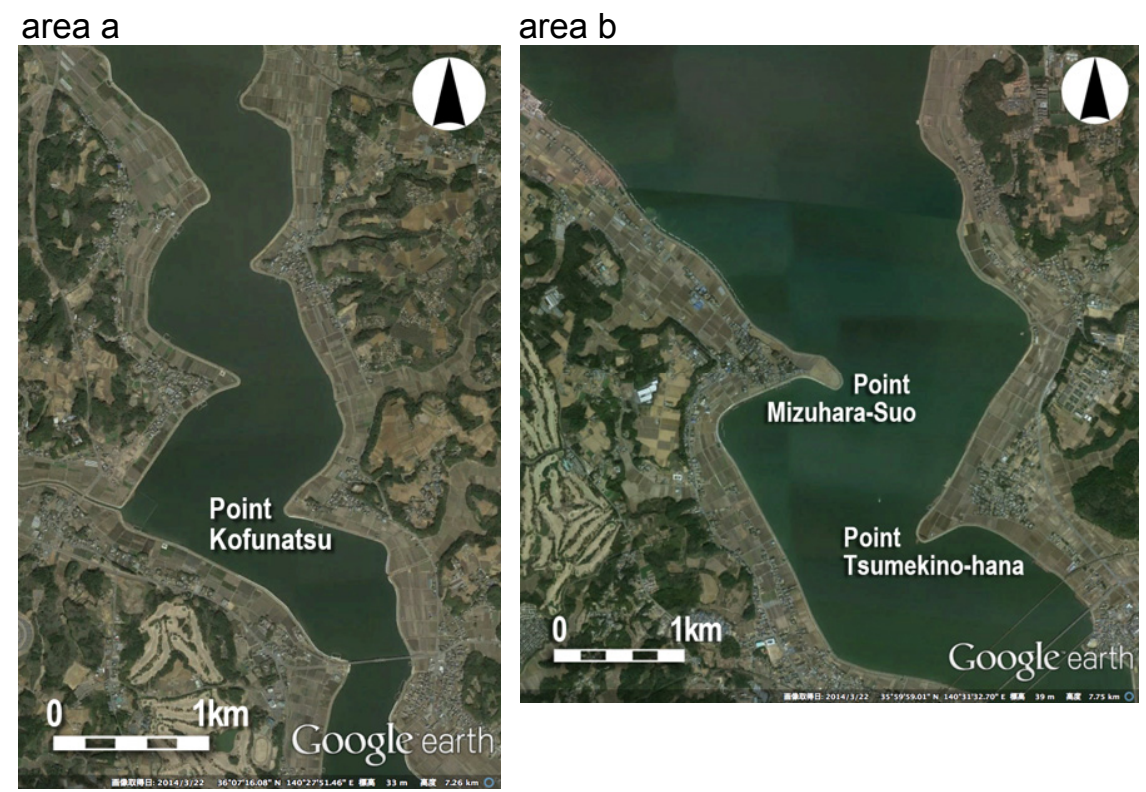

Figure 5. Enlarged satellite images of areas a and b in Lake Kitaura. 


\section{MODEL FOR PREDICTING LAKESHORE CHANGES}

For the calculation of the segmentation of a rectangular water body, the BG model employed in the calculation of oriented lakes (Uda et al. 2014) was used. Given a local fetch $F$ at a given point, the acceleration due to gravity $g$, and the wind velocity $U$, the significant wave height $H_{1 / 3}$ was calculated using Wilson's formula (Wilson 1965; Goda 2003).

$$
H_{1 / 3}=f(F, U)=0.30\left\{1-\left[1+0.004\left(g F / U^{2}\right)^{1 / 2}\right]^{-2}\right\}\left(U^{2} / g\right)
$$

In this calculation, a coordinate system of $\left(x_{w}, y_{w}\right)$ was set corresponding to the wave direction, as shown in Fig. 6, similarly to that in Uda et al. (2014), instead of a fixed coordinate system of $(x, y)$ for the calculation of beach changes. Neglecting the wave refraction effect, waves are assumed to propagate in the same direction as the wind. The fetch $F$ was added from upwind to downwind along the $x_{w}$-axis using Eq. (2) when the $x_{w}$-axis was divided by the mesh intervals $\Delta x_{\mathrm{w}}$. The index $i$ in Eq. (2a) is the mesh number along the $x_{w}$-axis. When a grid point was located on land and the downslope condition of $d Z / d x_{w} \leq 0$ was satisfied, the local fetch was reset as $F=0$ (Eq. 3). When the grid point was again located in the lake, $F$ was recalculated. By this procedure, the wave height becomes 0 on the lee of the cuspate forelands, and the wave-sheltering effect alone can be evaluated.

$$
\begin{gathered}
F^{(i+1)}=F^{(i)}+r \Delta x_{w} \\
r= \begin{cases}1 & (Z \leq 0) \\
0 & (Z>0)\end{cases} \\
F^{(i)}=0 \quad\left(\text { if } \quad \mathrm{Z} \geq 0 \text { and } d Z / d x_{w} \leq 0\right)
\end{gathered}
$$

For the sand transport equation, Eq. (4), which is expressed using the wave energy at the breaking point, was used, similar to the BG model proposed by Serizawa et al. (2006).

$$
\begin{gathered}
\vec{q}=C_{0} \frac{K_{s} P}{\tan \beta_{\mathrm{c}}}\left\{\tan \beta_{c} \overrightarrow{e_{w}}-|\cos \alpha| \overrightarrow{\nabla Z}\right\} \quad\left(-h_{c} \leq Z \leq h_{R}\right) \\
P=\varepsilon(Z)\left(E C_{g}\right)_{b} \tan \beta_{w} \\
\tan \beta_{w}=d Z / d x_{w} \quad\left(\tan \beta_{w} \geq 0\right)
\end{gathered}
$$

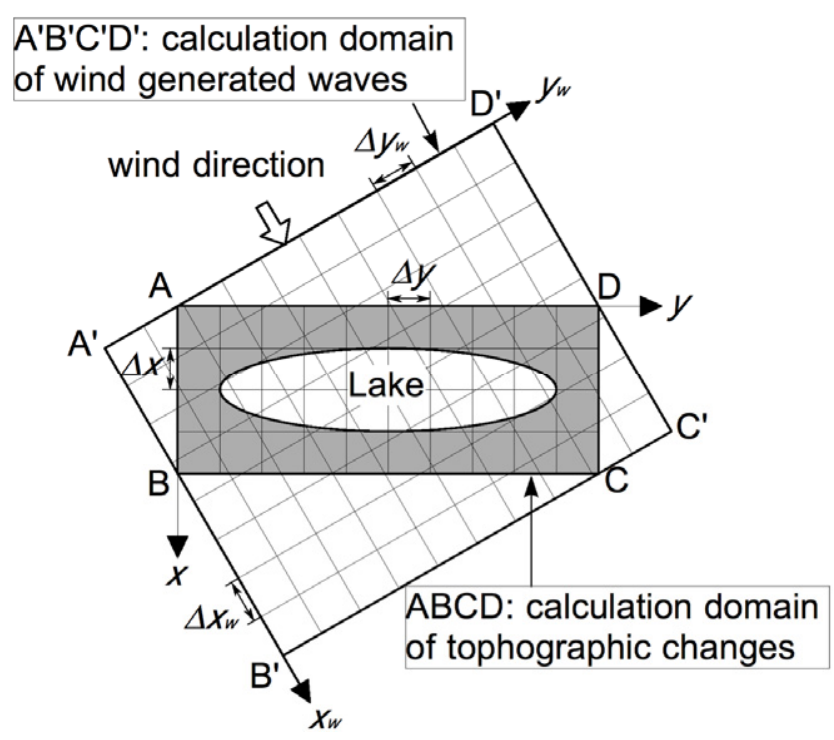

Figure 6. Definition of two coordinate systems. 
Here, $\vec{q}=\left(q_{x}, q_{y}\right)$ is the net sand transport flux, $Z(x, y, t)$ is the seabed elevation with reference to the still water level $(Z=0), \overrightarrow{\nabla Z}=(\partial Z / \partial x, \partial Z / \partial y)$ is the seabed slope vector, $\overrightarrow{e_{w}}$ is the unit vector of wave direction, $\alpha$ is the angle between the wave direction and the direction normal to the contour line, $|\cos \alpha|=\left|\overrightarrow{e_{w}} \cdot \overrightarrow{\nabla Z}\right| /|\overrightarrow{\nabla Z}|, x_{w}$ is the coordinate in the direction of wave propagation, $\tan \beta_{w}$ is the seabed slope measured in the direction of wave propagation, $\tan \beta_{c}$ is the equilibrium slope of sand, and $K_{s}$ is the longshore and cross-shore sand transport coefficient. $C_{0}$ is the coefficient for transforming the immersed weight expression to the volumetric expression $\left(C_{0}=1 /\left\{\left(\rho_{s}-\rho\right) g(1-p)\right\} ; \rho\right.$ is the seawater density, $\rho_{s}$ is the specific gravity of sand, $p$ is the sand porosity, and $g$ is the acceleration due to gravity), $h_{c}$ is the depth of closure, and $h_{R}$ is the berm height. The $P$ value (Eq. (5)) is the wave dissipation ratio per unit area of the seabed and time between $Z=-h_{\mathrm{c}}$ and $h_{R}$, where sand movement occurs (Serizawa et al. 2006). $\varepsilon(Z)$ in Eq. (5) is the depth distribution of sand transport and is defined so as to satisfy Eq. (7); in this study, a uniform distribution was employed (Eq. (8)).

$$
\begin{gathered}
\int_{-h_{c}}^{h_{R}} \varepsilon(Z) d Z=1 \\
\varepsilon(Z)=1 /\left(h_{c}+h_{R}\right) \quad\left(-h_{c} \leq Z \leq h_{R}\right)
\end{gathered}
$$

Moreover, assuming that $H_{1 / 3}$ is approximately equal to the breaker height $H_{b}$ and $\gamma$ is the ratio of breaker height to water depth, the wave energy flux at the breaking point $\left(E C_{g}\right)_{b}$ can be written as Eq. (9a).

$$
\begin{gathered}
\left(E C_{g}\right)_{b}=C_{1}\left(H_{b}\right)^{\frac{5}{2}} \approx C_{1}\left(H_{1 / 3}\right)^{\frac{5}{2}} \\
C_{1}=\frac{\rho g}{k_{1}} \sqrt{g / \gamma} \quad\left(k_{1}=(4.004)^{2}, \gamma=0.8\right)
\end{gathered}
$$

When $F$ and $H_{1 / 3}$ are calculated using the coordinate system of $\left(x_{w}, y_{w}\right)$ according to the wave direction, the wave power $P$ can be calculated and assigned to each grid point on the coordinates of $\left(x_{w}\right.$, $\left.y_{w}\right)$. The wave power $P$ at each grid point in the calculation of beach changes was interpolated from this distribution of $P$. The mesh intervals $\left(\Delta x_{w}, \Delta y_{w}\right)$ in the coordinate system of $\left(x_{w}, y_{w}\right)$ were taken to be the same as $(\Delta x, \Delta y)$. Finally, the sand transport and continuity equations, Eqs. (4) and (10), were solved on the $x-y$ plane by the explicit finite-difference method using the staggered mesh scheme.

$$
\frac{\partial Z}{\partial t}+\nabla \cdot \vec{q}=0
$$

In every step of the calculation of beach changes, the wind direction was reset using random numbers, and the $P$-value distribution was recalculated. In estimating the intensity of sand transport near the berm top and at the depth of closure, the intensity of sand transport was linearly reduced to 0 near the berm height or the depth of closure to prevent sand from being deposited in the zone higher than the berm height and the beach from being eroded in the zone deeper than the depth of closure (Uda et al. 2013). In this study, the wind direction at each step in the calculation of beach changes was determined using random numbers so as to satisfy the probability distribution function of the occurrence of a certain wind direction, although wind velocity was assumed to be constant. Furthermore, to clearly understand the gradual lakeshore changes over time, mean $\left(H_{1 / 3}\right)^{5 / 2}$ flux and sand transport flux were defined. Given $\overrightarrow{e_{w}}$ as a unit vector of the wave direction, $\overrightarrow{F_{w}}$ is written as Eq. (11).

$$
\overrightarrow{F_{w}}=\left(H_{1 / 3}\right)^{\frac{5}{2}} \overrightarrow{e_{w}}=\frac{1}{C_{1}}\left(E C_{g}\right)_{b} \overrightarrow{e_{w}}
$$

The vector $\overrightarrow{F_{w}}$ is proportional to the wave energy flux $\left(E C_{g}\right)_{b} \overrightarrow{e_{w}}$, and the time average of $\overrightarrow{F_{w}}$ between $t$ - $T$ and $t$ becomes 


$$
\left(\overrightarrow{F_{w}}\right)_{a v e}=\frac{1}{T} \int_{t-T}^{t} \overrightarrow{F_{w}} d t=\frac{1}{T} \int_{t-T}^{t}\left(H_{1 / 3}\right)^{\frac{5}{2}} \overrightarrow{e_{w}} d t
$$

The discretized expression of Eq. (12) becomes Eq. (13), when $T$ is expressed as $N \Delta t$.

$$
\left(\overrightarrow{F_{w}}\right)_{\text {ave }}=\frac{1}{N} \sum_{\text {istep }=\text { Nstep }-N+1}^{N \text { step }}\left\{\left(H_{1 / 3}\right)^{\frac{5}{2}} \overrightarrow{e_{w}}\right\}_{\text {istep }}
$$

Here, we set $N=1000$. The calculated value of Eq. (13) can be called the mean $\left(H_{1 / 3}\right)^{5 / 2}$ flux averaged over 1000 steps. The mean sand transport flux and elevation $Z$ can be calculated in the same manner.

\section{CALCULATION CONDITIONS}

Lakeshore changes owing to wind waves were predicted in a shallow lake of $3 \mathrm{~m}$ depth, assuming the berm height of $1 \mathrm{~m}$ and the initial beach slope of $1 / 20$. Random perturbations with the amplitude $\Delta Z=0.1 \mathrm{~m}$ were added to the slope between $Z=1$ and $-3 \mathrm{~m}$ in the initial bathymetry. Wind velocity was assumed to be $20 \mathrm{~m} / \mathrm{s}$, and wind blew from all directions between 0 and $360^{\circ}$ with the same probability of occurrence and intensity, and blew from the direction at an angle of $45^{\circ}$ relative to the principal axis of the rectangular lake with an elliptic probability of occurrence and intensity. Figure 7 shows the distribution of probability of occurrence of wave direction. The aspect ratio of the rectangular lake was assumed to be 5 . The calculation domain was discretized by $\Delta x=\Delta y=20 \mathrm{~m}$, and $\Delta t$ was set at $10 \mathrm{~h}$. The depth distribution of sand transport was assumed to be given by a uniform distribution throughout the depth, and the equilibrium slope was assumed to be $1 / 20$. Table 1 shows the calculation conditions. The wind velocity of $20 \mathrm{~m} / \mathrm{s}$ is the value at which a significant wave height of approximately $1 \mathrm{~m}$, the same as the berm height, could be generated, given the fetch distance of $4.6 \mathrm{~km}$, which is the distance along the diagonal of the initial rectangular water body in Cases 1 and 2 .

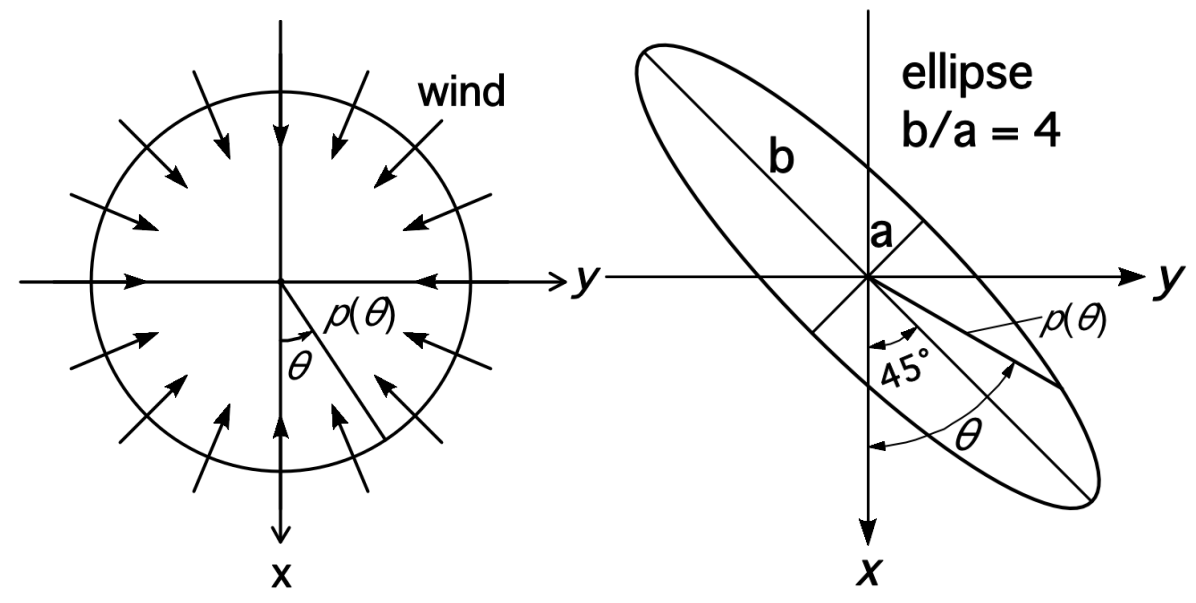

Figure 7. Probability distribution of occurrence of wind direction: (a) circular and (b) elliptic.

\begin{tabular}{|l|l|}
\hline \multicolumn{2}{|c|}{ Table 1. Calculation conditions. } \\
\hline Wind velocity & $20 \mathrm{~m} / \mathrm{s}$ \\
\hline Berm height $h_{R}$ & $1 \mathrm{~m}$ \\
\hline Depth of closure $h_{c}$ & $3 \mathrm{~m}$ \\
\hline Equilibrium slope $\tan \beta_{c}$ & $1 / 20$ \\
\hline $\begin{array}{l}\text { Coefficients of sand } \\
\text { transport }\end{array}$ & $\begin{array}{l}\text { Coefficient of longshore sand transport } K_{s}=0.2 \\
\text { Coefficient of cross-shore sand transport } K_{n}=K_{s}\end{array}$ \\
\hline Mesh size & $\Delta x=\Delta y=20 \mathrm{~m}$ \\
\hline Time intervals & $\Delta t=10 \mathrm{~h}$ \\
\hline Duration of calculation & $10^{6} \mathrm{hr}\left(10^{5}\right.$ steps) \\
\hline Boundary conditions & $\begin{array}{l}\text { Shoreward and landward ends } q_{x}=0 \\
\text { Right and left boundaries } q_{y}=0\end{array}$ \\
\hline
\end{tabular}




\section{RESULTS}

\section{Circular Distribution of Probability of Occurrence of Wind Direction (Case 1)}

Figure 8 shows the results of the calculation of the segmentation of a slender, rectangular water body with a longshore length of $4.5 \mathrm{~km}$ and width of $0.9 \mathrm{~km}$ (aspect ratio $=5$ ) while maintaining a constant wind velocity under the condition that the probability of occurrence of wind direction is given by a circular distribution. When wind waves are incident to the lakeshore, a number of cuspate forelands of irregular shapes developed along the shoreline after $5 \times 10^{3}$ steps. After $2 \times 10^{4}$ steps, the cuspate forelands merged with each other, resulting in their reduction in number, and sand bars of a hound's-tooth shape were formed. This development of cuspate forelands explains well the formation of the lakeshore, as shown in Figs. 2 and 5. After $4 \times 10^{4}$ steps, sand bars extended to the opposite shores, and the water body was about to separate into two lakes. After $5 \times 10^{4}$ steps, the water body had separated into two completely independent lakes, and the shape of the lakes became rounded. The lakeshore changes continued, and after $10^{5}$ steps, two completely rounded lakes were formed.

(a) 0 steps

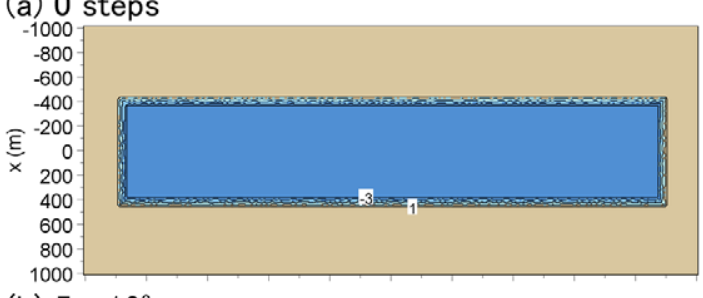

(b) $5 \times 10^{3}$ steps

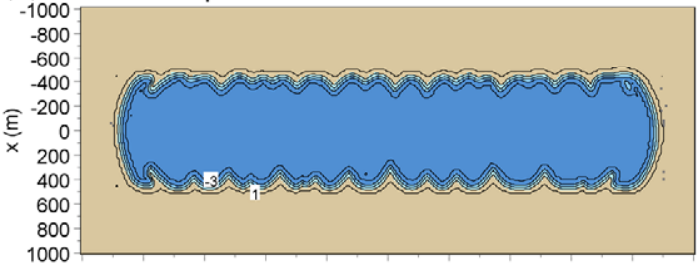

(c) $1 \times 10^{4}$ steps

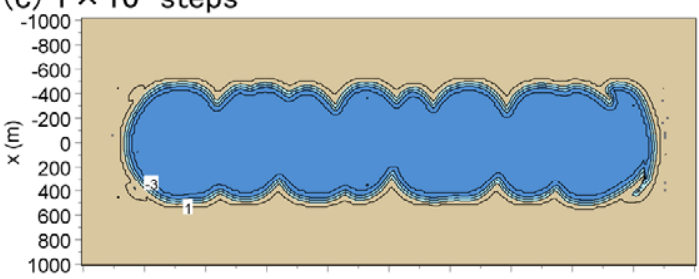

(d) $2 \times 10^{4}$ steps

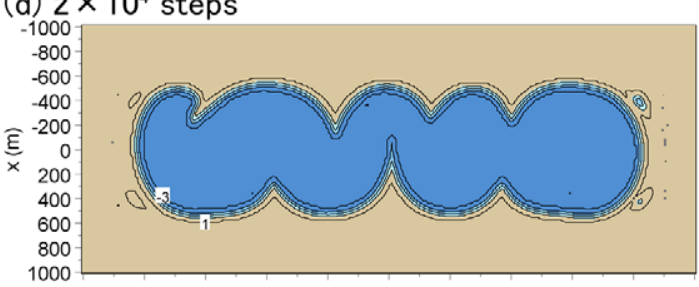

(e) $3 \times 10^{4}$ steps

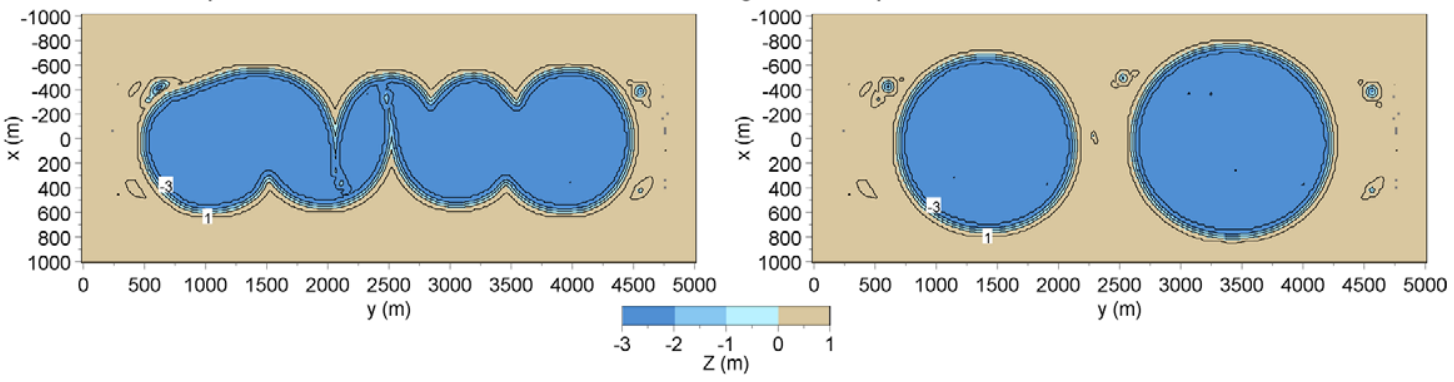

(f) $4 \times 10^{4}$ steps

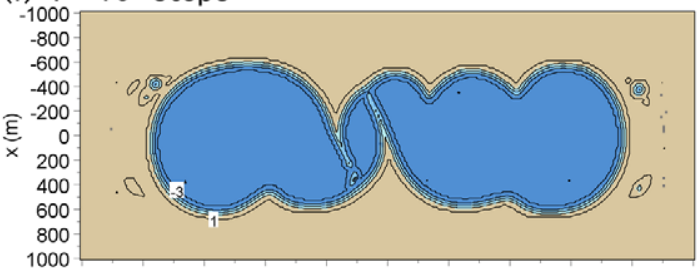

(g) $5 \times 10^{4}$ steps
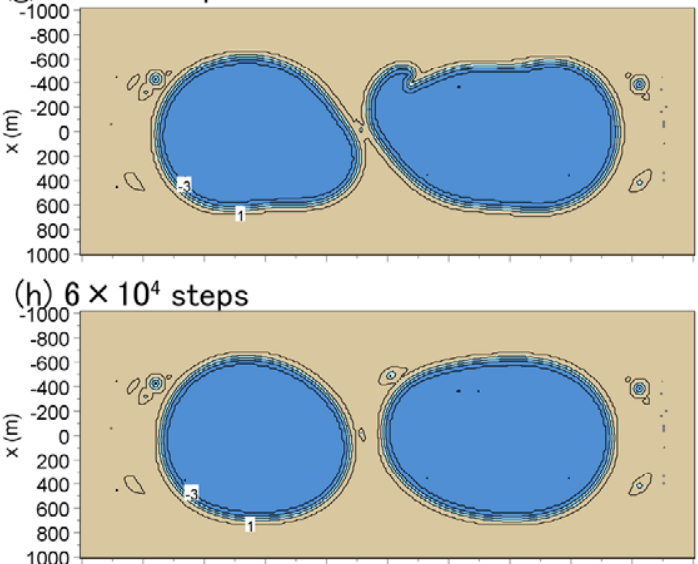

(i) $8 \times 10^{4}$ steps

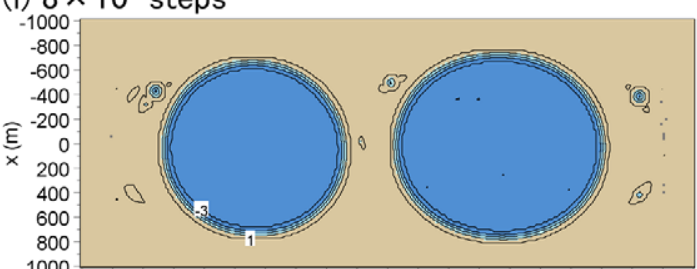

(j) $10^{5}$ steps

Figure 8. Lakeshore topography in Case 1 under uniform distribution of occurrence of wind direction and intensity. 
Uda et al. (2012) showed that a slender rectangular lake with an aspect ratio of 9 is segmented into four circular lakes. In this study, the aspect ratio is 5, and the lake was segmented into 2. Ashton et al. (2009) investigated the relationship between the number of lakes formed by the segmentation and the aspect ratio, and showed that the segmentation did not occur but a rounded lake was formed when the aspect ratio was smaller than 4 , and that the number of lakes was approximately given by half the aspect ratio when the aspect ratio was greater than 4 . By applying these results to the present case, the number of lakes becomes 2.5. The number of segmented lakes in the present case is 2, which agrees with the results obtained by Ashton et al. (2009).

Next, the wind fetch $F$, the significant wave height $H_{1 / 3}$, and the sand transport flux after 7 steps at the initial stage, $4 \times 10^{4}$ steps when two lakes were segmented, and $1 \times 10^{5}$ steps near the final stage were investigated. Figure 9 shows the distributions of $F, H_{1 / 3}$ and sand transport flux after 7 steps under the condition that wind blows from the direction of $260^{\circ}$. Because wind blows obliquely to the upward direction relative to the principal axis of the lake, $F$ takes the largest value at the top-left corner with the largest $H_{1 / 3}$ there. As a result, a large sand transport flux toward the left corner was generated.

Figure 10 shows the distributions of $F, H_{1 / 3}$ and sand transport flux after $\left(4 \times 10^{4}-20\right)$ steps immediately before the lake was segmented into two. At this step, wind blows from the direction of $72^{\circ}$ on the left side. Although cuspate forelands have already developed from both shores in the middle of the lake by this step, the wind fetch was shortened by the cuspate forelands, resulting in the reduction of the wave height on the lee of the cuspate forelands, whereas the left sides of the cuspate forelands were exposed to high waves, and strong longshore sand transport was induced as well as the sand transport toward the right corner of the lake.

(a) Wind fetch: $F(\mathrm{~m})$ (after 7 steps, $\theta_{w}=260^{\circ}$ )

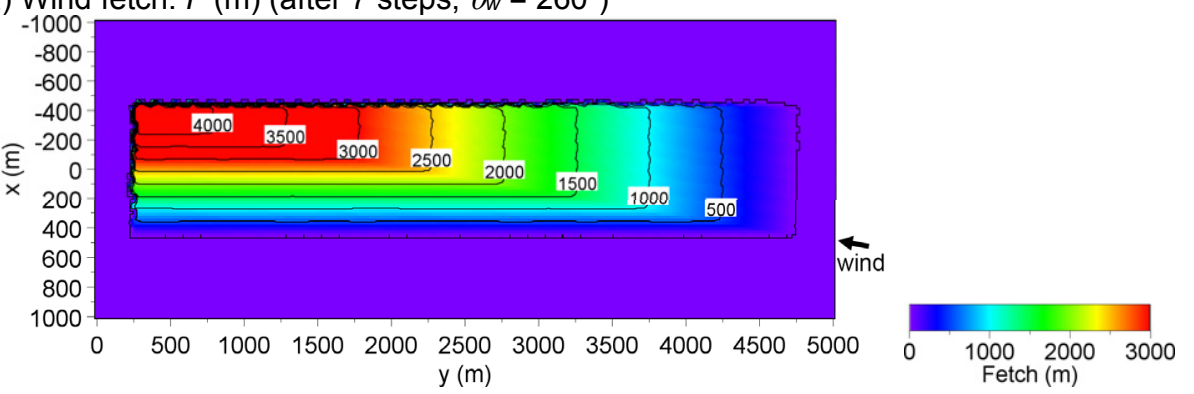

(b) Significant wave height: $H_{1 / 3}(\mathrm{~m})$ (after 7 steps, $\theta_{w}=260^{\circ}$ )

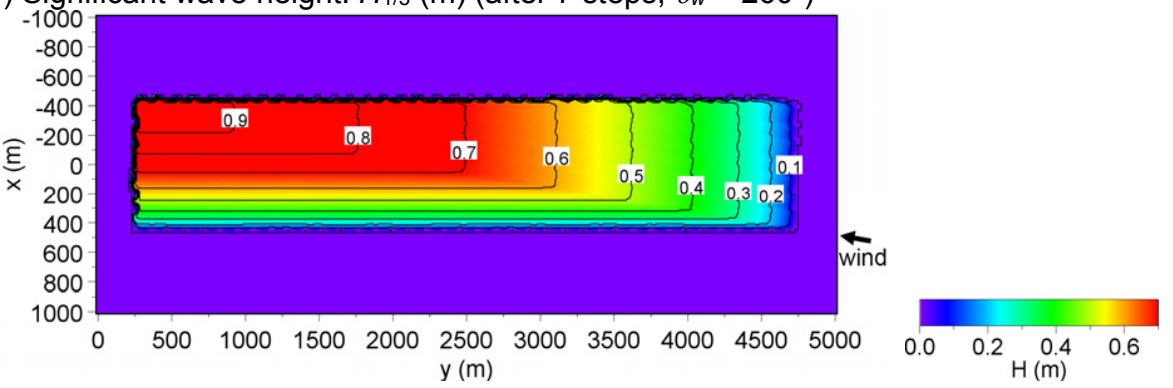

(c) Sand transport flux (after 7 steps, $\theta_{w}=260^{\circ}$ )

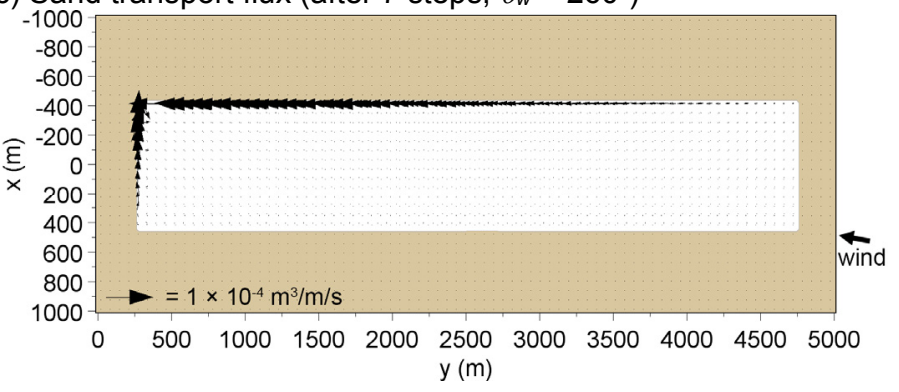

Figure 9. Wind fetch $F$, significant wave height $H_{1 / 3}$ and sand transport flux when $\theta_{\mathrm{w}}=260^{\circ}$ at initial stage of segmentation after 7 steps. 
After $4 \times 10^{4}$ steps, the wind direction changed to the direction of $280^{\circ}$, as shown in Fig. 11 , while reversing the direction. A strong longshore sand transport occurred on the right side of the cuspate foreland, where once it was located in the shadow zone together with a strong longshore sand transport along the concave shoreline at the left end of the lake.

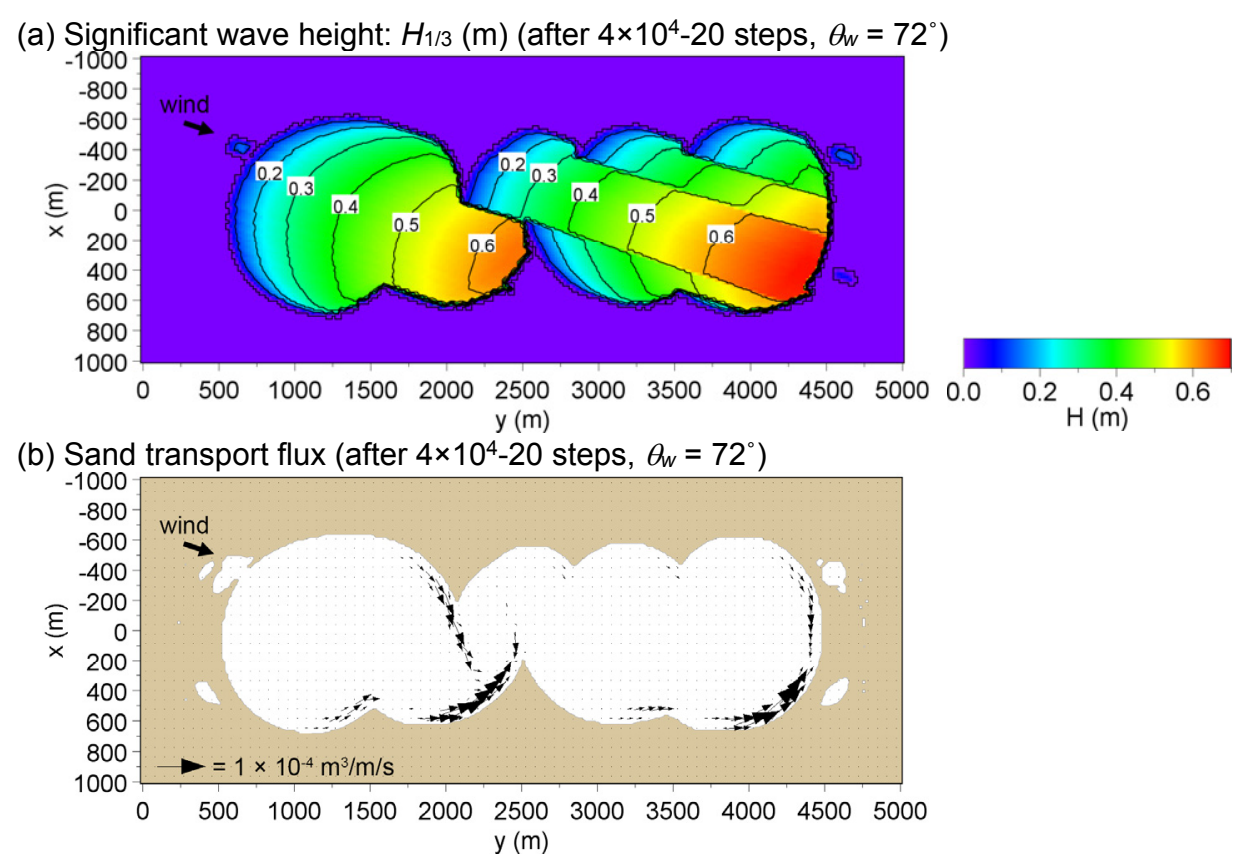

Figure 10. Significant wave height $H_{1 / 3}$ and sand transport flux when $\theta_{w}=72^{\circ}$ at a stage of segmentation after $\left(4 \times 10^{4}-20\right)$ steps.

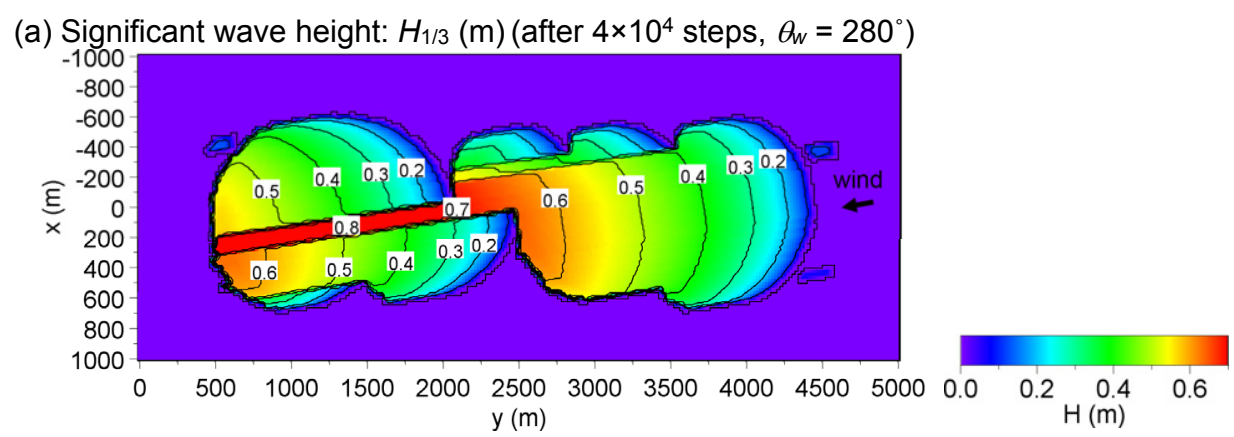

(b) Sand transport flux (after $4 \times 10^{4}$ steps, $\theta_{w}=280^{\circ}$ )

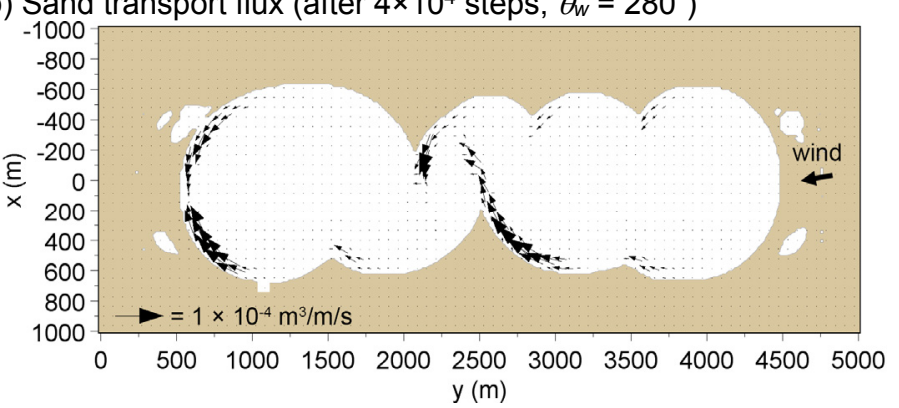

Figure 11. Significant wave height $H_{1 / 3}$ and sand transport flux when $\theta_{w}=280^{\circ}$ at a stage of segmentation after $4 \times 10^{4}$ steps. 
Finally, Fig. 12 shows the distribution of $H_{1 / 3}$ and sand transport flux after $1 \times 10^{5}$ steps. Because the wind blew from the direction of $280^{\circ}$, wave height increased around the left corners of segmented lake with increasing sand transport toward the concave shoreline at the left end. Thus, at the final stage, the shape of the circular lake became stable, but sand was still moving along the shoreline in a dynamically equilibrium state. As a result of wind blowing from random directions, the shape of the segmented lakes became circular.

Figure 13 shows the mean $\left(H_{1 / 3}\right)^{5 / 2}$ flux averaged over 1000 steps at six stages between $1 \times 10^{3}$ and $1 \times 10^{5}$ steps after a rectangular lake segmented into two circular lakes. The arrows in the figure show the direction of the flux, and the color corresponds to the intensity of the flux. After $1 \times 10^{3}$ steps, outward flux was generated radially from the central part of the lake with a symmetric distribution, and the time-averaged flux at the central part was 0 because of the cancellation of the sum of the vector.

After $2 \times 10^{4}$ steps, the mean $\left(H_{1 / 3}\right)^{5 / 2}$ flux was equivalent on both sides of the central cuspate foreland, facilitating the development of the cuspate foreland. After $4 \times 10^{4}$ steps, the cuspate forelands further developed, and the direction of the mean $\left(H_{1 / 3}\right)^{5 / 2}$ flux approached the direction normal to the shoreline. Finally, after $1 \times 10^{5}$ steps, the direction of the mean $\left(H_{1 / 3}\right)^{5 / 2}$ flux became normal to the shoreline of the rounded lake.

Figure 14 shows the mean sand transport flux after the same number of steps as the flux in Fig. 12. After $1 \times 10^{3}$ steps, the sand transport flux was large near the corners of the rectangular lake, but after $2 \times 10^{4}$ steps it increased not only near the corners but also on both sides of the developing cuspate forelands. After $4 \times 10^{4}$ steps, immediately before the segmentation into two lakes, the intensity of sand transport significantly increased around the cuspate forelands and the corners of the lake. After $1 \times 10^{5}$ steps, sand transport flux markedly decreased and the lake converged to a stable form.

\section{Elliptic Distribution of Probability of Occurrence of Wind Direction (Case 2)}

Another case was considered in which wind blows from the direction of $45^{\circ}$ with respect to the principal axis of the slender lake, i.e., the probability of occurrence of wind direction is given by an elliptic distribution. Uda et al. (2014) predicted the formation of the oriented lakes (Seppälä 2004) using the BG model, and showed that the oriented lakes could develop when the probability of occurrence of wind direction is given by an elliptic distribution because wind blows from the direction oblique to the principal axis of the lakes. In this study, assuming the same distribution of the probability of occurrence, the calculation of the segmentation was carried out.

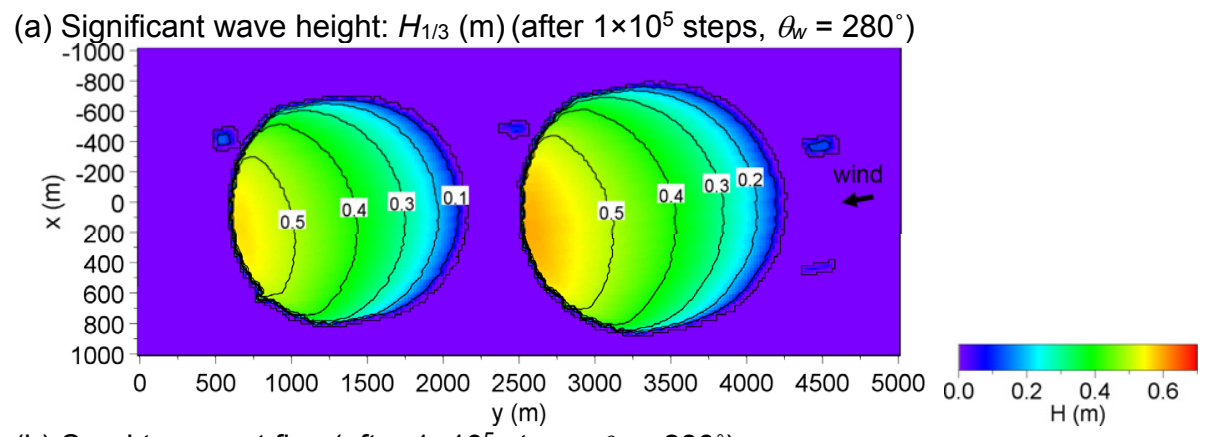

(b) Sand transport flux (after $1 \times 10^{5}$ steps, $\theta_{w}=280^{\circ}$ )

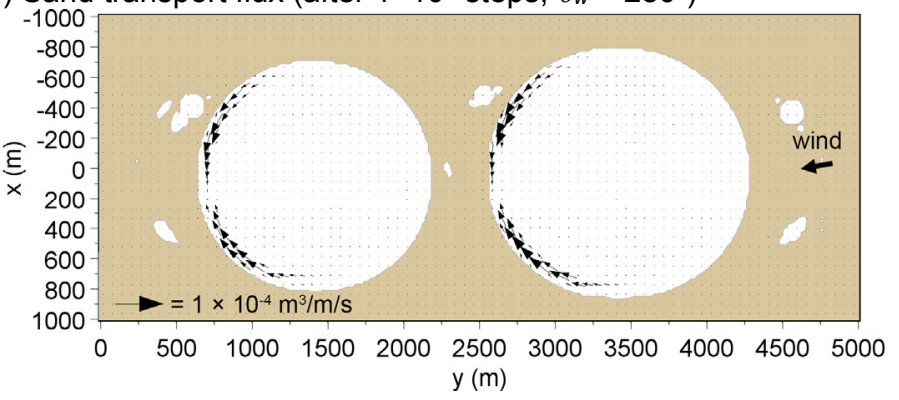

Figure 12. Significant wave height $H_{1 / 3}$ and sand transport flux when $\theta_{\mathrm{w}}=280^{\circ}$ at final stage of segmentation after $1 \times 10^{5}$ steps. 
(a) $1 \times 10^{3}$ steps

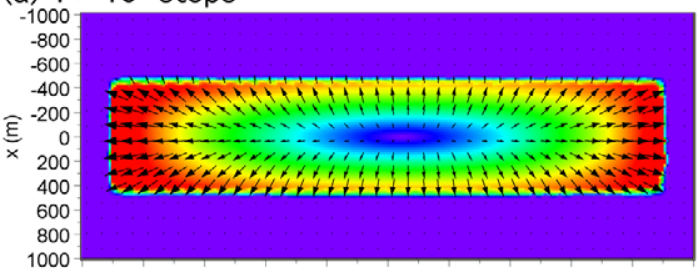

(b) $2 \times 10^{4}$ steps

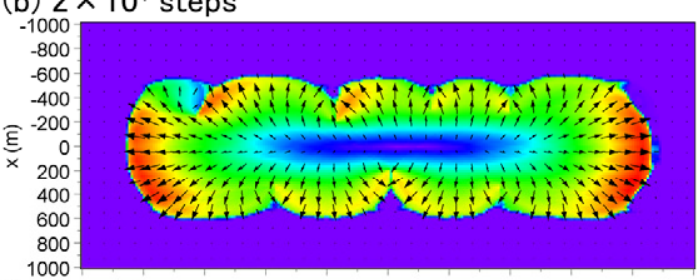

(c) $3 \times 10^{4}$ steps

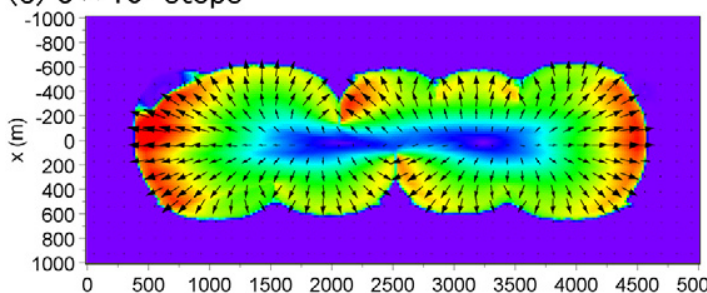

$\begin{array}{lllllllllll}0 & 500 & 1000 & 1500 & 2000 & 2500 & 3000 & 3500 & 4000 & 4500 & 5000\end{array}$ $y(m)$ (d) $4 \times 10^{4}$ steps

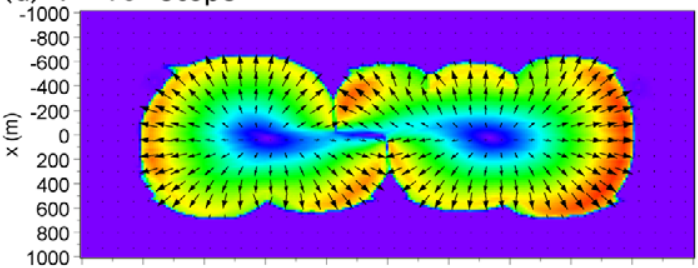

(e) $5 \times 10^{4}$ steps

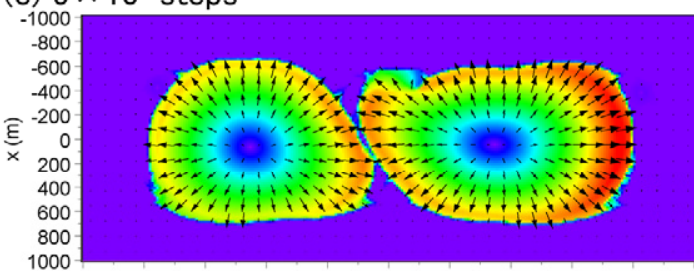

(f) $1 \times 10^{5}$ steps

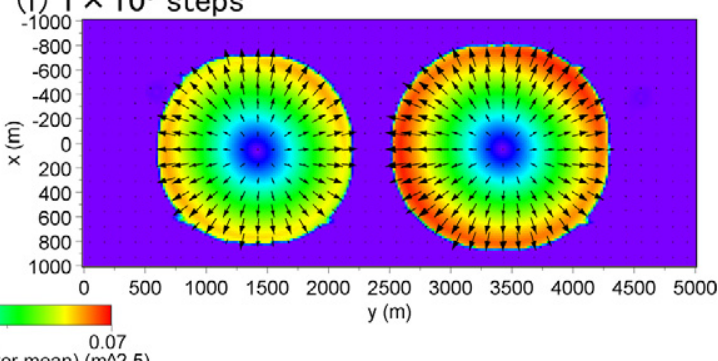

Figure 13. Distribution of mean $\left(H_{1 / 3}\right)^{5 / 2}$ flux in Case 1.

(a) $1 \times 10^{3}$ steps

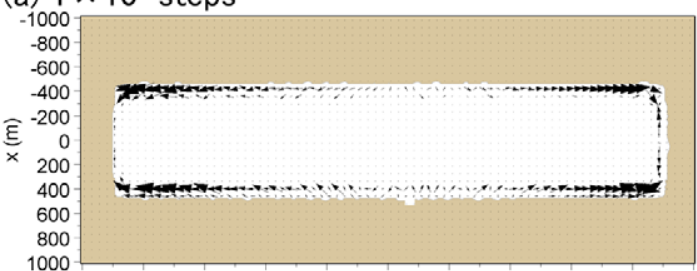

(b) $2 \times 10^{4}$ steps

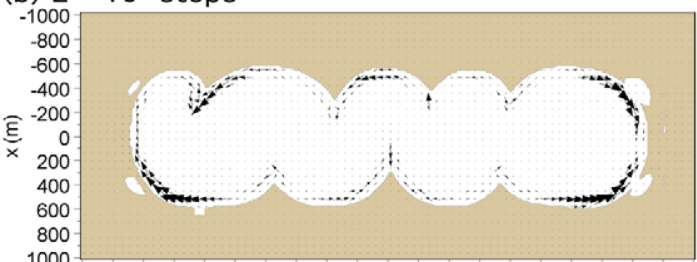

(c) $3 \times 10^{4}$ steps

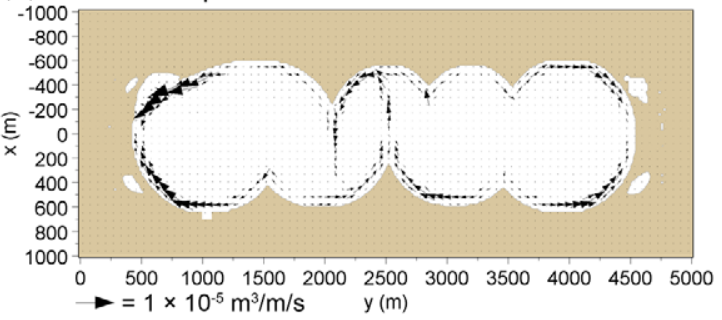

(d) $4 \times 10^{4}$ steps

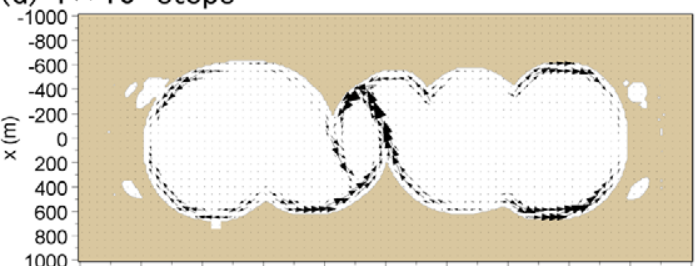

(e) $5 \times 10^{4}$ steps

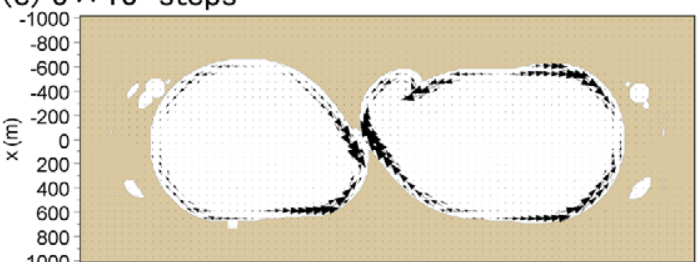

(f) $1 \times 10^{5}$ steps

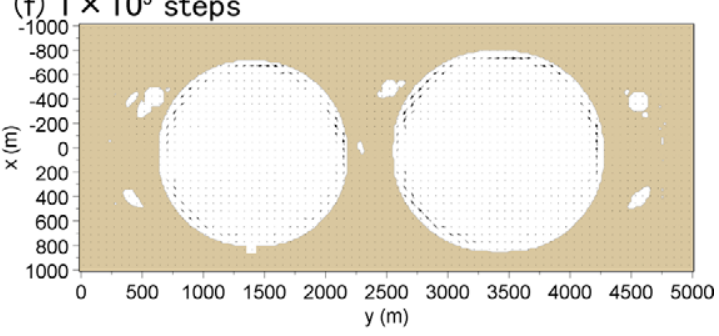

Figure 14. Mean sand transport flux in Case 1.

Figure 15 shows the shape of the lake averaged over 1000 steps under the same initial and calculation conditions as Case 1. This figure corresponds to Fig. 8 in Case 1. After $10^{3}$ steps, infinitesimal irregular variations can be seen along the upper and lower shores. After $1 \times 10^{4}$ steps, 
cuspate forelands of asymmetric form developed on both shores, and inclined rightward and leftward on the lower and upper shorelines, respectively. After $2 \times 10^{4}$ steps, the cuspate forelands merged to increase their scale and they moved rightward and leftward on the lower and upper shorelines, respectively. This result is in good agreement with the results obtained by Uda et al. (2012) concerning the development of sand spits and cuspate forelands with rhythmic shapes that are due to the shoreline instability. Because the principal axis of wind direction is at an angle of $45^{\circ}$ relative to the shoreline and the effect of wind blowing from land to the lake can be neglected along the lower shoreline, the oblique component of waves incident from the left takes a high probability compared with that of waves incident from the right. As a result, rightward sand transport was predominant in causing the formation of a cuspate foreland of asymmetric shape along the $y$-axis, and rightward movement of the cuspate foreland took place. The formation of a cuspate foreland with an asymmetric shape corresponds to the formation of a lagoon, as shown in Fig. 2, and the formation of the lakeshore in Lake Kitaura. Moreover, the cuspate foreland markedly developed at the right end on the lower shoreline and at the left end on the upper shoreline because of long fetch distance and large wave intensity.

(a) $1 \times 10^{3}$ steps

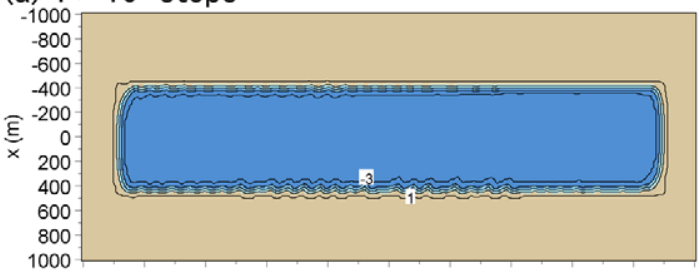

(b) $1 \times 10^{4}$ steps

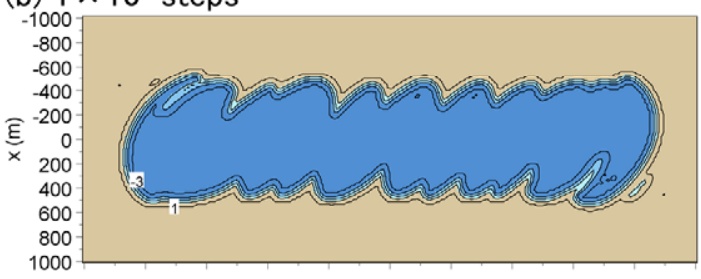

(c) $2 \times 10^{4}$ steps

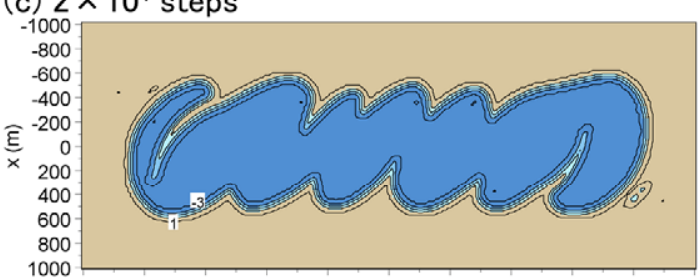

(d) $3 \times 10^{4}$ steps

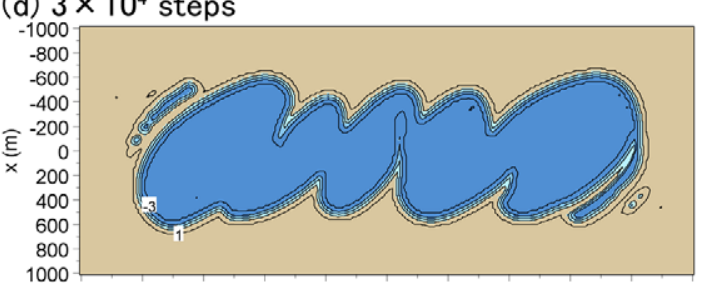

(e) $4 \times 10^{4}$ steps

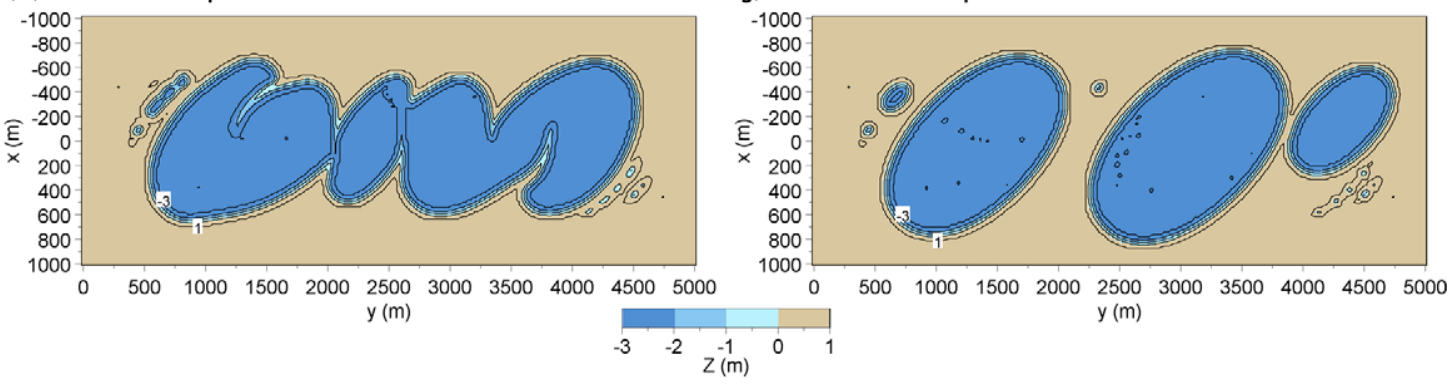

(f) $5 \times 10^{4}$ steps

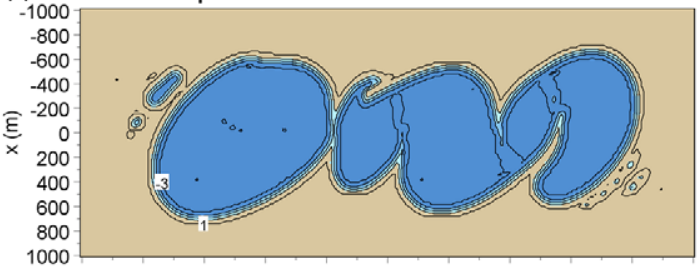

(g) $6 \times 10^{4}$ steps

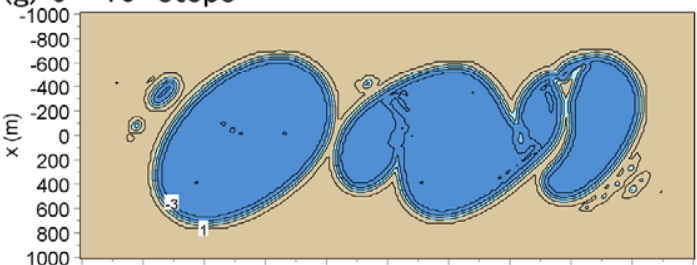

(h) $8 \times 10^{4}$ steps

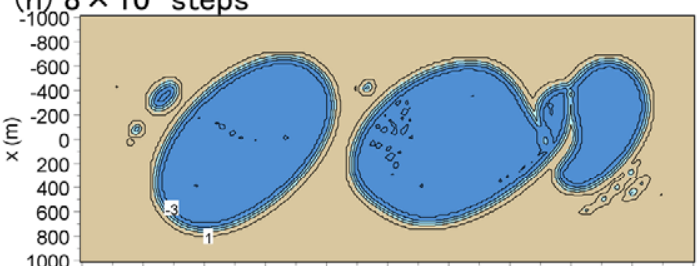

(i) $1 \times 10^{5}$ steps

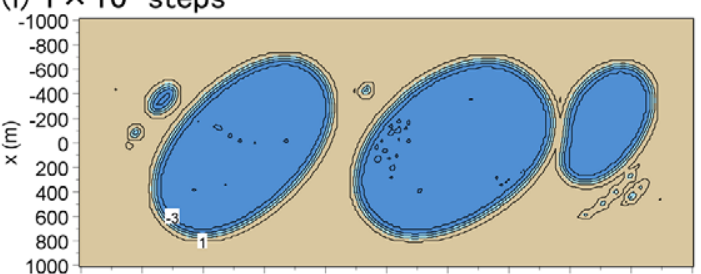

(j) $1.5 \times 10^{5}$ steps

Figure 15. Mean lakeshore topography in Case 2 under circular distribution of occurrence of wind direction. 
After $3 \times 10^{4}$ steps, the cuspate forelands near the end of the lake connected to the ends and formed a barrier island, whereas the cuspate foreland in the central part markedly extended to the opposite shore. After $5 \times 10^{4}$ steps, the water body on the left side was segmented to have an elliptic form, and the size of the cuspate foreland at the central part on the lower shoreline, that once developed, began to decrease. After $1.5 \times 10^{5}$ steps, two large lakes and one small lake were formed. Three segmented lakes with an elliptic shape are similar to each other in terms of the parallel direction of the principal axes. This direction of the principal axes is normal to the principal axis of the probability distribution of occurrence of wind direction, as shown in Fig. 7. The formation of the lakes with an elliptic shape with parallel principal axes explains the development process of the elliptic lakes observed in Chukchi Sea shown in Fig. 1.

Figure 16 shows the distribution of the mean $\left(H_{1 / 3}\right)^{5 / 2}$ flux averaged over 1000 steps. After $10^{3}$ steps, a strong flux occurred toward the corners of the rectangular lake. Because the principal axis of the wind direction makes an angle of $45^{\circ}$ relative to the lower shoreline, the flux toward the corners of the lake developed along the upper and lower shorelines. When the cuspate foreland began to develop under this condition, the flux on the left side is greater than that on the right side of the cuspate foreland, and

(a) $1 \times 10^{3}$ steps

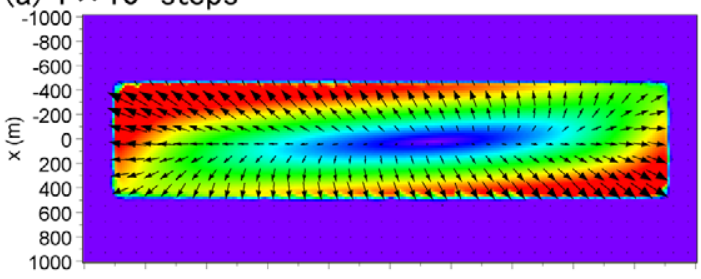

(b) $1 \times 10^{4}$ steps

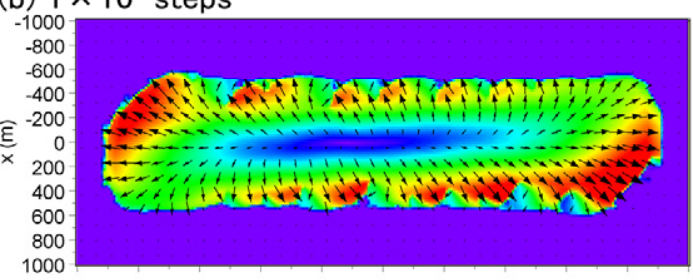

(c) $2 \times 10^{4}$ steps

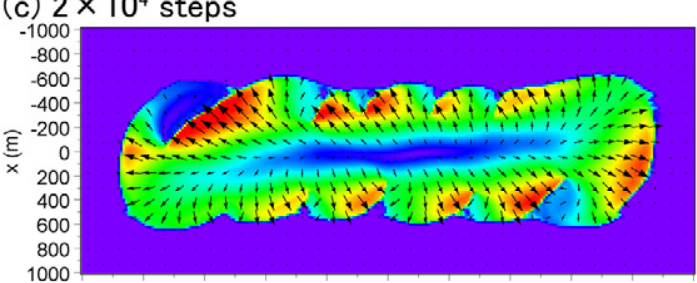

(d) $3 \times 10^{4}$ steps

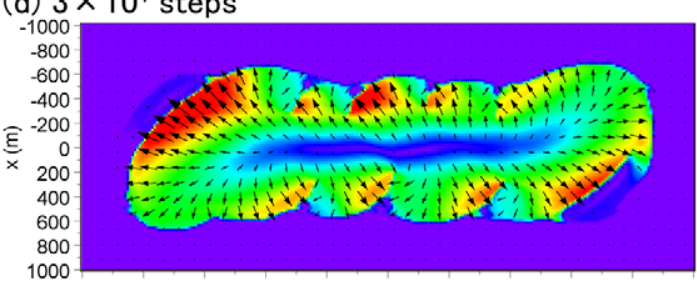

(e) $4 \times 10^{4}$ steps

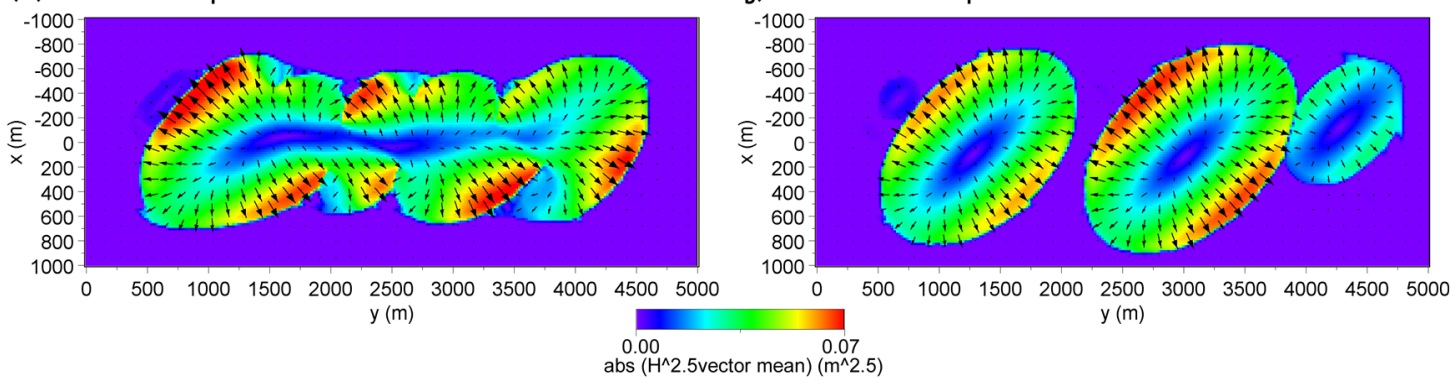

(f) $5 \times 10^{4}$ steps

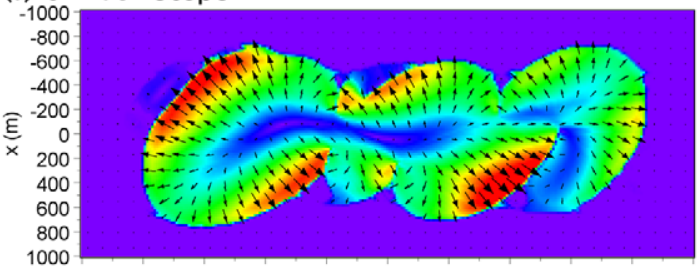

(g) $6 \times 10^{4}$ steps

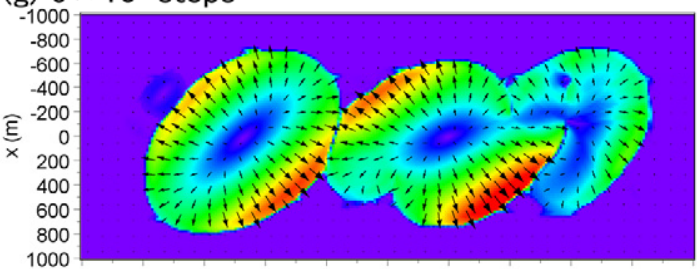

(h) $8 \times 10^{4}$ steps

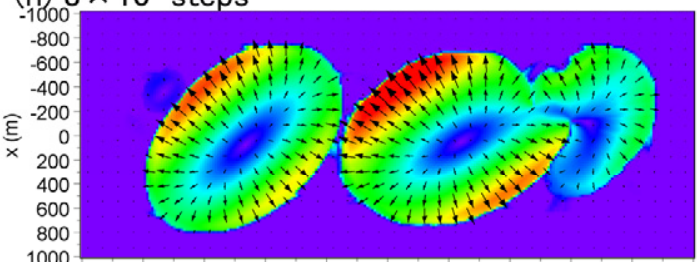

(i) $1 \times 10^{5}$ steps

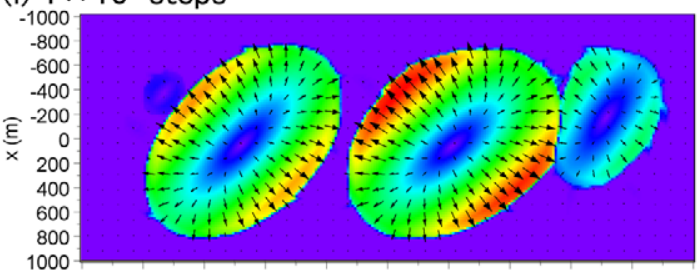

1000

(j) $1.5 \times 10^{5}$ steps

\section{$-1000-$}

Figure 16. Distribution of mean $\left(H_{1 / 3}\right)^{5 / 2}$ flux in Case 2. 
the cuspate foreland moved rightward with increasing scale, as typically shown during $(1-3) \times 10^{4}$ steps After $3 \times 10^{4}$ steps, the cuspate forelands were almost connected to the right end of the lake. Similarly, on the upper shoreline, the cuspate forelands were almost connected to the left end. Similar changes continued after $4 \times 10^{4}$ steps, but after $6 \times 10^{4}$ steps, the mean $\left(H_{1 / 3}\right)^{5 / 2}$ flux along the shoreline of the left water body was approximately balanced. After $8 \times 10^{4}$ steps, the shape of the lake at the left end became elliptic, and the direction of the mean $\left(H_{1 / 3}\right)^{5 / 2}$ flux became normal to the shoreline, resulting in a stable shape of the lake. Finally, after $1.5 \times 10^{5}$ steps, three elliptic lakes were segmented while the direction of the mean $\left(H_{1 / 3}\right)^{5 / 2}$ flux was normal to the shoreline.

Figure 17 shows the distribution of the mean sand transport flux averaged over 1000 steps. In response to the distribution of the mean $\left(H_{1 / 3}\right)^{5 / 2}$ flux, sand transport toward the corners of the rectangular lake occurred after $10^{3}$ steps. However, between $10^{4}$ and $3 \times 10^{4}$ steps, sand transport in the directions that accelerate the development of the cuspate foreland occurred along the lower and upper shorelines. As the water body approaches an elliptic form over time, the rate of sand transport decreased, and after $1.5 \times 10^{5}$ steps, the sand transport became nil, and the shape of the lake converged to become stable.

(a) $1 \times 10^{3}$ steps

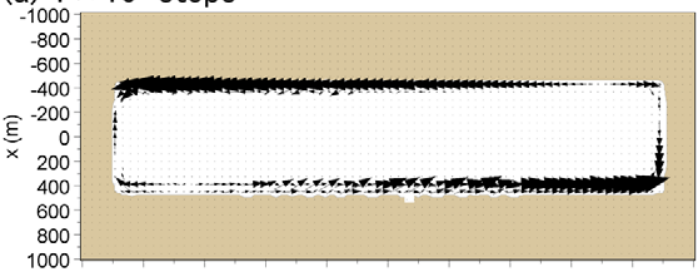

(b) $1 \times 10^{4}$ steps

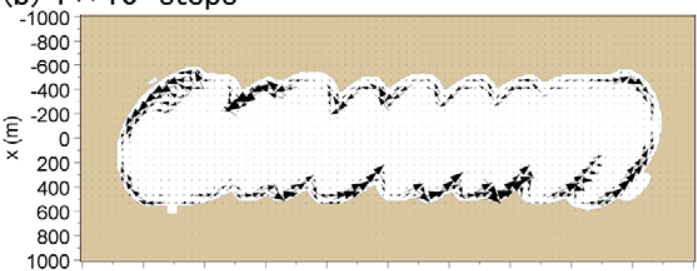

(c) $2 \times 10^{4}$ steps

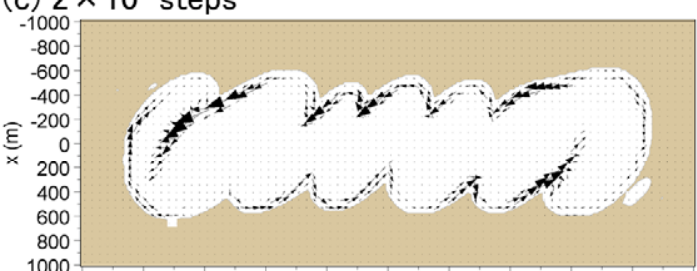

(d) $3 \times 10^{4}$ steps

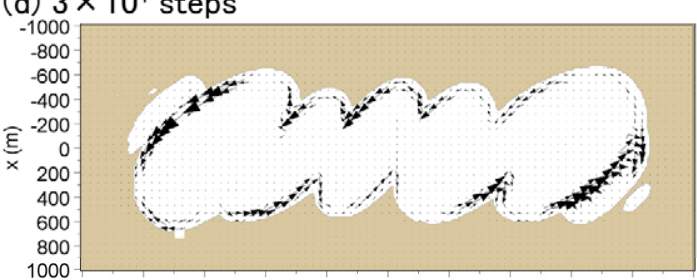

(e) $4 \times 10^{4}$ steps

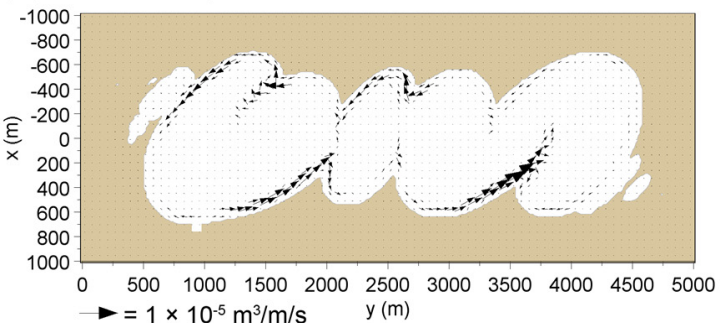

(f) $5 \times 10^{4}$ steps

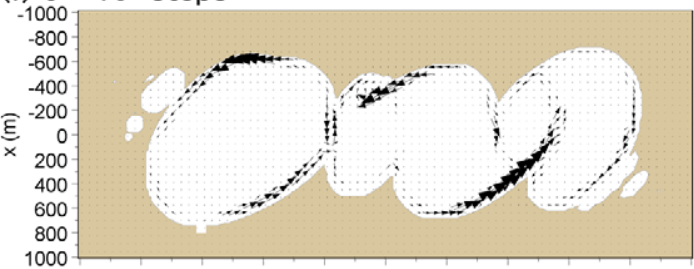

(g) $6 \times 10^{4}$ steps

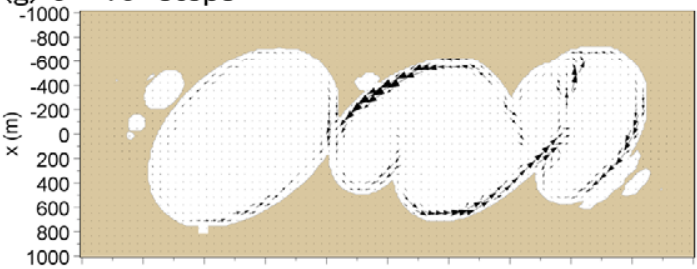

(h) $8 \times 10^{4}$ steps

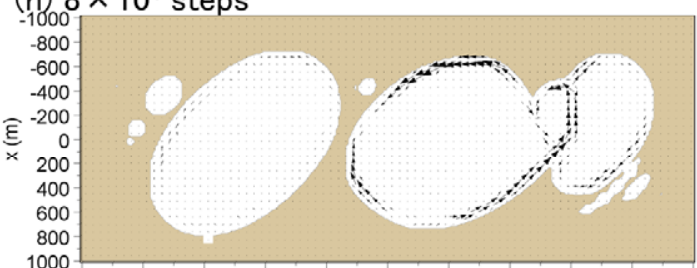

(i) $1 \times 10^{5}$ steps

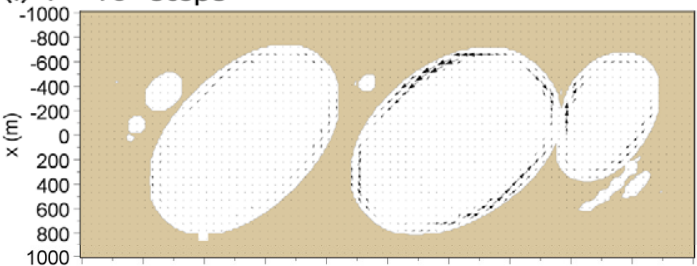

(j) $1.5 \times 10^{5}$ steps

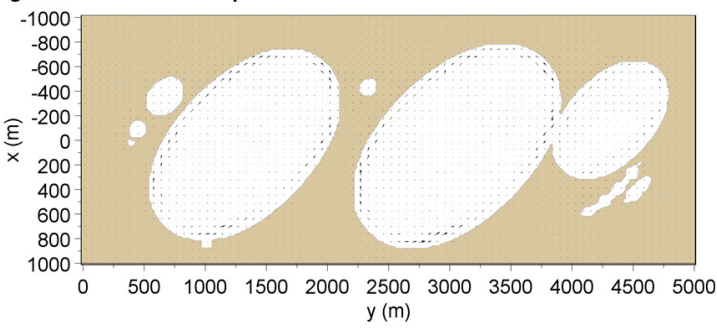

Figure 17. Mean sand transport flux in Case 2. 


\section{CONCLUSIONS}

The BG model was used to predict the segmentation of a rectangular water body by wind waves when the probability of occurrence of wind direction is given by a circular or elliptic distribution. The changes in wave field and sand transport flux over time were calculated in detail to investigate the wave-sheltering effect of the cuspate forelands. It was concluded that a rectangular water body segmented into circular or elliptic lakes when the probability of occurrence of wind direction was given by a circular or elliptic distribution, respectively. In the latter case, the direction of the principal axis of an elliptic lake becomes perpendicular to the direction of the principal axis in the probability distribution of occurrence of wind direction.

\section{REFERENCES}

Ashton, A., A.B. Murray, and O. Arnault. 2001. Formation of coastline features by large-scale instabilities induced by high-angle waves, Nature, Vol. 414, 296-300.

Ashton, A., and A.B. Murray. 2006. High-angle wave instability and emergent shoreline shapes: 1. Modeling of sand waves, flying spits, and capes, J. Geophys. Res., 111, F04011, doi: 10.1029/2005JF000422.

Ashton, A., A.B. Murray, R. Littlewood, D.A. Lewis, and P. Hong. 2009. Fetch limited selforganization of elongate water bodies, Geology, 37, 187-190.

Goda, Y. 2003. Revisiting Wilson's formulas for simplified wind-wave prediction, J. Waterway, Port, Coastal and Ocean Eng., 129(2), 93-95.

Seppälä, M. 2004. Wind as a Geomorphic Agent in Cold Climates, Cambridge University Press, p. 358.

Serizawa, M., T. Uda, T. San-nami, and K. Furuike. 2006. Three-dimensional model for predicting beach changes based on Bagnold's concept, Proceedings of $30^{\text {th }}$ International Conference on Coastal Engineering, ASCE, 3155-3167.

Uda, T., M. Serizawa, and S. Miyahara. 2012. Numerical simulation of three-dimensional segmentation of elongated water body using BG model, Proceedings of $33^{\text {rd }}$ International Conference on Coastal Engineering, ASCE, sediment.65, 1-11.

Uda, T., M. Serizawa, S. Miyahara, and T. San-nami. 2013. Prediction of segmentation and mergence of shallow water bodies by wind waves using BG model, Proc. Coastal Dynamics 2013, Paper No. $166,1729-1740$.

Uda, T., M. Serizawa, T. San-nami, and S. Miyahara. 2014. Prediction of formation of oriented lakes, Proceedings of $34^{\text {th }}$ International Conference on Coastal Engineering, ASCE, 1-12.

Wilson, B. W. 1965. Numerical prediction of ocean waves in the North Atlantic for December, 1959, Deut. Hydrogr. Zeit, Jahrgang 18, Heft 3, 114-130.

Zenkovich, V. P. 1967. Processes of Coastal Development, 751p., Interscience Publishers, New York. 